\title{
Development of Massive Open Online Course Model: Muslim Way of Life in Food Consumption to Promote Cultural Understanding of Undergraduate Students
}

\author{
Ophat Kaosaiyaporn, Wasant Atisabda, and Kittisak Na Patthalung
}

\begin{abstract}
The purpose of this research was to develop the Massive Open Online Course (MOOC) model: Muslim way of life in food consumption to promote cultural understanding of undergraduate students. The aims of this research were: 1) to develop the MOOC model: Muslim way of life in food consumption to promote cultural understanding of undergraduate students, 2) to study the cultural understanding after studying with the MOOC model: Muslim way of life in food consumption to promote cultural understanding of undergraduate students, and 3 ) to study the students' satisfaction with the MOOC model: Muslim way of life in food consumption to promote cultural understanding of undergraduate students. The sample consisted of 227 students of private and public universities in five southernmost provinces of Thailand.

The findings revealed as follows: 1) MOOC model: Muslim way of life in food consumption to promote cultural understanding of undergraduate students consisted four components: Content resources, Development and delivery tools resources, Implementation resources and Evaluation, 2) There was significant differences between pretest and posttest of cultural understanding scores of higher students at $\mathbf{. 0 5}$ level, and 3) the students' satisfaction was ranked at highest level.
\end{abstract}

Index Terms-Massive open online course, Muslim way of life in food consumption, cultural understanding.

\section{INTRODUCTION}

The open system theory in education, especially interacting with culture, has started once Thailand enters the ASEAN Community of immense and colorful cultural diversity in 2015 under the ASEAN Charter which shared commitment and collective responsibility in enhancing regional peace, sharing and caring community, security and prosperity exceptionally cultural identity. The Vision of an ASEAN Socio-Cultural Community embedded goal of a community of cohesive, equitable and harmonious societies, and bound together in solidarity for deeper understanding of the richness of ASEAN's history, languages, culture and common values [1].

Thailand hosts many different ethnic communities and cultures such as native Thai, Thai Chinese, Thai Malays, and hill tribe peoples. They are homogenous and share a common culture. Central Thai language is using for standard

Manuscript received November 27, 2017; revised January 9, 2018. This work was supported in part by Prince of Songkla University.

The authors are with the Department of Educational Technology, Faculty of Education, and Research Center for Educational Innovations and Teaching and Learning Excellence, Prince of Songkla University, Thailand (e-mail: ophat.k@psu.ac.th, vassan.a@psu.ac.th, kittisak.n@psu.ac.th). language in communication. They are loyalty to Thai monarch and obey the same law. In the same time each ethnic group also has its own custom and tradition. Thai Malays are Muslim; they speak Malay, wear traditional Malay dress and lead a way of life similar to the Malays. Thai Chinese, Thai of Chinese origin, still maintain old traditions for example; worshiping Chinese deities, pray to ancestors, and celebrating Chinese New Year. Native Thai have distinct cultures influenced by regions. For example, the North or northern Thai people speak their own dialect, wear the northern Thai dress or Lanna costume, prefer eating sticky rice, and possess their own northern Thai arts which are notably different from other regions. This idea of society is called Multicultural Society [2]-[4].

The emergence of new communication and computing technologies, we are becoming increasingly accustomed to new buzzwords to describe technology based learning. One of the latest buzzwords is "MOOC," short for "Massive Open Online Course". [5] MOOCs are delivered through an open and distributed e learning environment. The design, development, implementation, and evaluation of open and distributed learning systems, such as MOOCs, require a thoughtful analysis and investigation of how to use the attributes and resources of the Internet and digital technologies in concert with instructional design principles and issues important to various dimensions of online learning environments. [6], [7]

A Massive Open Online Course model was first introduced in 2002 emerged from the institutes aiming at unlimited knowledge to general public. The Massive Open Online Course model often emphasized open-access features for all students. Massachusetts Institution of Technology (MIT) and Yale are also the providers of this model through MIT Open Courseware and Open Yale Course for everyone who is interested to learn without credit. Many institutes believe that Massive Open Online Courses provide supporting interactions and preparations among students associated with Open Learning Concept of Open University, England. Various universities in Asia also developed this concept in their programs. For example, the University of Tokyo established UT Open Courseware website contained collection of free access knowledge and Thailand Cyber University promoted Self-paced learning courses which are diversified into more than 600 subjects such as humanities and social science. [8], [9]. While there are benefits, MOOCs currently face several challenges. [7] The four major problems associated with MOOCs: 1) high dropout rates; 2) lack of a financial model; 3) credentialing, and 4) academic integrity. However, failure in elearning courses is more often 
associated with poor execution of some aspects of the initial project design and dissemination/implementation [10].

The researcher aimed to develop the Massive Open Online Course model: Muslim way of life in food consumption to promote cultural understanding of undergraduate students in order to align with a higher education among multicultural society. Furthermore, multicultural society can be the strength to sustainably underpin the learners to experience and understand different ways of life to live peacefully together in one community.

\section{The Purposes OF THE StUdy}

1) To development the Massive Open Online Course model: Muslim way of life in food consumption to promote cultural understanding of undergraduate students.

2) To study the cultural understanding after studying with the Massive Open Online Course model: Muslim way of life in food consumption to promote cultural understanding of undergraduate students.

3) To study the students' satisfaction with the Massive Open Online Course model: Muslim way of life in food consumption to promote cultural understanding of undergraduate students.

\section{RESEARCH METHODOLOGY}

The study aims to develop the Massive open online course model: Muslim way of life in food consumption to promote cultural understanding of undergraduate students. The research method consisted of two phases:

Phase 1: Analyzing and synthesizing related literature and documents regarding the development of the MOOC model: Muslim way of life in food consumption to promote cultural understanding of undergraduate students

TABLE I: THE POPULATION AND SAMPLES OF THIS RESEARCH
\begin{tabular}{|c|c|c|}
\hline & Number & Percentage \\
\hline Year of study & & \\
\hline - First year & 109 & 48 \\
\hline - Second year & 66 & 29 \\
\hline - Third year & 34 & 15 \\
\hline - Fourth year & 18 & 8 \\
\hline Sex & & 42 \\
\hline - Male & 95 & 58 \\
\hline - Female & 132 & 42 \\
\hline Religion & & 57 \\
\hline - Buddhist & 96 & 1 \\
\hline - Muslim & 128 & \\
\hline - Christian & 3 & \\
\hline
\end{tabular}

The researcher analyzed and synthesized the concepts, principles, theories, and research studies concerning on four area; 1) scope of content, 2) content development, 3) implement, and 4) evaluation. The researcher also studied more about Implementation resources, Development and delivery tools resources, and Content resources.

Phase 2: Developing the MOOC model: Muslim way of life in food consumption to promote cultural understanding of undergraduate students.

The researcher used the information from Phase 1 to create the model which would be submitted to 21 specialists who are higher education's administrators and instructors to get any appropriate feedback from their evaluation.

Phase 3: Implementing a trial version of MOOC model: Muslim way of life in food consumption to promote cultural understanding of undergraduate students on the representative samples

Table I showed that the population and samples of this research are 227 students of private and public universities in five southernmost provinces of Thailand; most students, 128 (57\%) are Muslim, followed by 96 (42\%) students who are Buddhists.

\section{RESEARCH RESULT}

1) The MOOC model: Muslim way of life in food consumption to promote cultural understanding of undergraduate students derived from the collecting, analyzing and synthesizing related data.
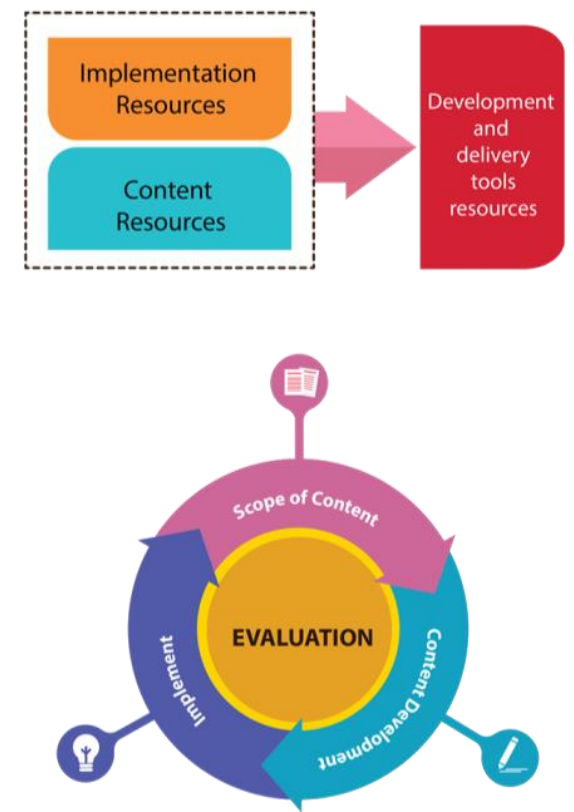

Fig. 1. A massive open online course model: Muslim way of life in food consumption to promote cultural understanding of undergraduate students.

Fig. 1 showed the model of massive open online course: Muslim way of life in food consumption to promote cultural understanding of undergraduate students and described as follows [4];

The model composes of 1) the content is distributed mainly by video-lecture format and focus on: a complete course, e-learning, module content, learning media, sources of information and references, 2) the learning tools are varied such as, a learning management system and an Open Source Software or Free Software application for the development, operation, and delivery of educational programs 3) Implementation; Intellectual Property Rights of the model can be applied as follows; 1) Content resources can be delivered through internet as e-program and multimedia, 2) Sources of development and delivery, and 3) Open licensing of content

The model includes 3 types of learning sources: 1) Content resources, 2) Development and delivery tools resources, and 3) Implementation resources consist of 4 steps of 
implementation: 1) Scope of content, 2) Content Development, 3) Implementation by using Creative Common license, and 4) evaluation

1.1.1 Scope of content can be described as follows;

1.1.1.1 The content is defined into 4 topics; 1.1.1.1.1 Halal-Haram,

1.1.1.1.2 Muslim consumption behavior,

1.1.1.1.3 Halal food processing,

1.1.1.1.4 Approval of Halal certification.

1.1.1.2 Scope of content/Presentation; the contents and activities of a model are as Open Courseware by gathering various learning content and resources to open freely for students without any violation of intellectual property rights, all contents have to be referred to the sources or received permission from the copyright owner before any distribution.

1.1.1.3 Authorship; the contents can be both single and multiple authorship. The authorship has to be clarified in case of the writer or researcher earned research fund if the content belong to a funder or writer.

1.1.1.4 Granularity; the scale or level of content present or block each time which depends on data management of each program such as word processing and Portable Document Format-PDF.

1.1.1.5 Media specification is the way to determine any tool using in model development. This will be non-commercial or free of charge service as Open Source Software. The tools are (1) e-Book, (2) Website, (3) Picture, and (4) Video.

1.1.2 Content Development details are as follows:

1.1.2.1 The sampling users in this research are student in universities. It is important to specify a sample group due to the different learning capacity of each age level, same level of age and education can be more accurate in research development.

1.1.2.2 Level of content difficulty should be aligned with the users' capacities.

1.1.2.3 Open Licenses: Open Licenses or Creative Commons is the permission that allows promoting and using the learning resources and structures in an online course of Massive Open Online Course (MOOC) free of charge to the public under some conditions decided by the providers. The use of Massive Open Online Course would most benefit to all countries once the Open Licenses are accepted worldwide. A Massive Open Online Course Model: Muslim Way of Life in food consumption to promote cultural understanding of undergraduate students is considered as worldwide standard of acceptance according to

1.1.2.3.1 give the author or licensor the credits (CC BY),

1.1.2.3.2 give the author or licensor the credits and distribute derivative works only under a license identical (CC BY-SA),

1.1.2.3.3 give the author or licensor the credits and copy, distribute, display, and perform only verbatim copies of the work, not derivative works or remixes (CC BY-ND),

1.1.2.3.4 give the author or licensor the credits and copy, distribute, display, and perform the work and make derivative works and remixes only for non-commercial purposes (CC BY-NC),

1.1.2.3.5 give the author or licensor the credits and distribute derivative works only under a license identical only for non-commercial purposes (CC BY-NC-SA), and

1.1.2.3.6 give the author or licensor the credits and copy, distribute, display, and perform only verbatim copies of the work, not derivative works or remixes for non-commercial purposes (CC BY-NC-ND)

1.1.2.4 Content and media development

1.1.2.4.1 Analyzing is needed for content development

1.1.2.4.2 Specialists evaluate the content and give any necessary feedback before applying as a MOOC Model: Muslim Way of Life in Food Consumption to Promote Cultural Understanding of Undergraduate Students

1.1.2.4.3 Development of MOOC Model: Muslim Way of Life in Food Consumption

1.1.2.2.4 Media and tool would be evaluated before using. 1.1.3 Implementation

The distribution of a Massive Open Online Course will be done by internet as it is the fastest mean of communication and the Medias are;

1.1.3.1 Lesson and web designing: The most important factor for anyone to understand a content is "Attention", it is a cause of positive imagination. Main content should be on the upper part of webpage, a background with minimum texture and cool color tone is easy to read, the same font should be used entire page, content is arranged properly, click buttons are orderly and easy to click. Questions are used to lead users' attention and related links are required to let users study more on unsolved questions or further information. The factors to create interaction of users and learners are: 1) Introduction, 2) Objective, 3) Content, 4) Activity, 5) Resources, 6) Evaluation, 7) Lecturer and author's profile, 8) Bulletin Board, 9) Chat Room and Discussion Board providing for the learners to exchange knowledge and concept among them.

1.1.3.2 Video: Question is the way to create an attention in video. Questions should be inserted in 3 parts; (1) before starting each clip, (2) between significant contents, and (3) at the end of each clip. Questions are used to repeat and revise experiences the learners have and connect to new knowledge, this related to concepts of George Brown [11], George T. Ladd and Hans O. Anderson [12] that questions are used as the tool to make learners to understand a message given by teacher also make learners to recall and understand their previous knowledge. Questions should be inserted at right position to alert learners to pay attention to what teacher want to communicate. Learning ability and revision process of learners would be established. Questions also encourage intuitive thinking of learners and allow them to arrive at the conclusion of a lesson. A color tone of video background is one thing that should not be overlooked. Font and background color should be contrast, not in the same tone as in color wheel. Video length should not be more than 10 minutes as the learners can concentration well in this period.

1.1.3.3 e-book is consist of

1.1.3.3.1 Cover Page,

1.1.3.3.2 Index,

1.1.3.3.3 Appendix,

1.1.3.3.4 Image,

1.1.3.3.5 Sound,

1.1.3.3.6 Video,

1.1.3.3.7 Flipping Effects, 


\subsection{Hyperlink.}

\subsubsection{Evaluation}

Evaluation is used according to an actual output and performance of learners from a test and an examination.

2) Results of a Massive Open Online Course model: Muslim way of life in food consumption to promote cultural understanding of undergraduate students.

The result from study the cultural understanding after studying with the Massive Open Online Course model: Muslim way of life in food consumption to promote cultural understanding of undergraduate students. The researcher studied several factors regarding knowledge and understanding of Muslim way of life in food consumption as follows:

2.1 The Muslim consumer culture in Thailand,

2.2 Knowing Halal food,

2.3 A meaning of "Haram",

2.4 A permissible in traditional Islamic law applied to food,

2.5 Any act or thing forbidden or proscribed by Islamic law,

2.6 Knowledge about Islamic tradition that affects diets and consumption of Muslim in Thailand,

2.7 Halal food processing,

2.8 Halal certification application and requirement,

2.9 Halal certification approval process,

2.10 An understanding of Islamic dietary laws in general.

TABLE II: THE RESUlt OF CULTURAL UNDERSTANDING AFTER STUDYING WITH THE MASSIVE OPEN ONLINE COURSE MODEL: MUSLIM WAY OF LIFE IN Food CONSUMPTION to PRomote Cultural Understanding OF UNDERGRADUATE STUDENTS

\begin{tabular}{|l|c|c|c|c|c|}
\hline \multirow{2}{*}{ the cultural understanding } & \multicolumn{2}{|c|}{ Pretest } & \multicolumn{2}{|c|}{ Posttest } & \multirow{2}{*}{ t-test } \\
\cline { 2 - 6 } & $\overline{\mathbf{X}}$ & S.D. & $\overline{\mathbf{X}}$ & S.D. & \\
\hline $\begin{array}{l}\text { 1. The Muslim consumer } \\
\text { culture in Thailand. }\end{array}$ & 3.42 & 0.79 & 4.85 & 0.39 & 25.52 \\
\hline 2. Knowing Halal food. & 3.54 & 0.61 & 4.93 & 0.24 & 33.28 \\
\hline 3. A meaning of "Haram". & 2.86 & 0.95 & 4.86 & 0.43 & 29.12 \\
\hline $\begin{array}{l}\text { 4. A permissible in traditional } \\
\text { Islamic law applied to food. }\end{array}$ & 2.88 & 0.86 & 4.81 & 0.42 & 31.30 \\
\hline $\begin{array}{l}\text { 5. Any act or thing forbidden or } \\
\text { proscribed by Islamic law. }\end{array}$ & 3.50 & 0.73 & 4.84 & 0.38 & 24.94 \\
\hline $\begin{array}{l}\text { 6. Knowledge about Islamic } \\
\text { tradition that affects diets and } \\
\text { consumption of Muslim in } \\
\text { Thailand. }\end{array}$ & 3.54 & 0.68 & 4.86 & 0.36 & 26.50 \\
\hline 7. Halal food processing. & 2.99 & 0.86 & 4.80 & 0.42 & 30.00 \\
\hline $\begin{array}{l}\text { 8. Halal certification application } \\
\text { and requirement. }\end{array}$ & 2.68 & 0.98 & 4.81 & 0.41 & 30.04 \\
\hline $\begin{array}{l}\text { 9. Halal certification approval } \\
\text { process. }\end{array}$ & 2.51 & 1.04 & 4.93 & 0.24 & 33.50 \\
\hline $\begin{array}{l}\text { 10. An understanding of Islamic } \\
\text { dietary laws in general. }\end{array}$ & 3.09 & 0.48 & 4.90 & 0.29 & 45.89 \\
\hline
\end{tabular}

In Table II the result shows that the average score of learners in term of culture understanding after applying a MOOC model associated to Muslim way of life is higher at a significance level of 0.05

3) Results of the students' satisfaction with MOOC model: Muslim way of life in food consumption to promote cultural understanding of undergraduate students.
TABLE III: THE RESULT OF THE STUDENTS' SATISFACTION WITH MOOC MODEL: MUSLIM WAY OF LIFE IN FOOD CONSUMPTION TO PROMOTE CULTURAL UNDERSTANDING OF UNDERGRADUATE STUDENTS.

\begin{tabular}{|l|c|c|c|}
\hline \multicolumn{1}{|c|}{ Students' satisfaction } & $\overline{\mathbf{X}}$ & S.D. & Meaning \\
\hline $\begin{array}{l}\text { Overall satisfaction of Presentation } \\
\text { issue }\end{array}$ & 4.86 & 0.39 & highest level \\
\hline $\begin{array}{l}\text { Overall satisfaction of Content } \\
\text { understanding issue }\end{array}$ & 4.85 & 0.25 & highest level \\
\hline $\begin{array}{l}\text { Overall satisfaction of implement it in } \\
\text { daily life issue }\end{array}$ & 4.92 & 0.23 & highest level \\
\hline Overall Satisfaction & 4.87 & 0.25 & highest level \\
\hline
\end{tabular}

Table III showed that the average overall of students' satisfaction of MOOC model: Muslim way of life in food consumption to promote cultural understanding of undergraduate students was ranked at highest level $(\overline{\mathrm{X}}=4.87$, S.D. $=0.25)$.

\section{RECOMMENDATIONS}

From the implications of these results, the researcher proposed suggestions for implementation and further research as follows:

1) Research implementation

1.1 This model is flexible and can be adjusted according to the level of learners and course to achieve specific learning objective.

1.2 The teachers and learners have to be well prepared before an implementation of this model.

1.3 Prior to implementing this model, the meeting should be set to explain the learning process and pattern, activities, goal, and objective to teachers, learners, and all related person so they will understand the benefits of this model in a way of encouraging the learning skill among learners.

1.4 The participation of all parties is a key to the effectiveness and success of a model implementation.

2) Further research recommendation.

2.1 The case study of this model reported to emerge learning skills among learners so further research should be conducted to encourage other different value or context such as culture awareness and problem solving.

2.2 A MOOC should be repeated at a certain level of development to serve the increasing number and broad range of students in the future.

\section{REFERENCES}

[1] O. Kaosaiyaporn, J. Na-Songkhla, and L. Boonthong, "Open educational resources development model for an inquiring cultural skill of higher education students," Procedia - Social and Behavioral Sciences, vol. 174. pp. 2031-2035, 2015.

B. Yongyuan. (March 2016). The encouragement a children development in the context of cultural diversity. [Online]. Available: http://www.cf.mahidol.ac.th/autopage/file/WedJuly2008-22-18-5-4art icel-004.pdf

[2] O. Kaosaiyaporn, J. Klaisang, and J. Na-Songkhla, "Factors of virtual networks for multicultural classrooms to enhance knowledge construction and cultural awareness for graduate students," Technical Education Journal King Mongkut's University of Technology North Bangkok, vol. 3, no. 1, pp. 48-56, 2012.

[3] O. Kaosaiyaporn, J. Na-Songkhla, and P. Prommakan, "The development of open educational resources of cultural learning model that enhance inquiring skills of higher students skills," Journal of Education Prince of Songkla University, vol. 28, no. 2, pp. 38-47, 2017. 
[4] J. R. Corbeil, M. E. Corbeil, and B. H. Khan, The MOOC Case Book: Case Studies in MOOC Design, Development and Implementation, Ronkonkoma, NY: Linus Books, 2015.

[5] B. H. Khan, User Interface Design for Virtual Environments: Challenges and Advances, Hershey, PA: IGI Global Publishing, 2012.

[6] W. D. Milheim, "Massive open online courses (MOOCs): Current applications and future potential," Educational Technology, vol. 53, no. 3, pp. 38-42, 2013.

[7] J. Klaisang, "MOOCs pedagogy: From OCW, OER to MOOCs as learning tools for digital learners. Strengthening Learning Quality: Bridging Engineering and Education," Thailand Cyber University, pp. 276-285, 2013

[8] S. Sombuntham and J. Klaisang. "Thailand Cyber University and the best practice for open online courseware's services" presented at the AROOC 2012 titled Thailand Cyber, Jan. 21, 2013.

[9] A. J. Romiszowski, "How's the elearning baby? Factors leading to success or failure of an educational technology innovation," Educational Technology, vol. 44, no. 1, pp. 5-27, 2004.

[10] G. Brown, A Statistical Analysis in Psychology and Education, 5th.ed., Tokyo: Kosaido Printing, 1975.

[11] T. L. George and H. O. Anderson, "Determining the level of inquiry in teachers' questions," Journal of Research in Science Teaching, vol. 7, no. 4, pp. 395-400, 1970.

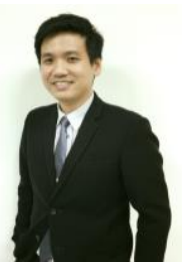

Ophat Kaosaiyaporn is an assistant professor and also the chair of master's program in educational technology and communications at the Department of Educational Technology, Faculty of Education and also the Secretary and Committee Member of the Research Center for Educational Innovations and Teaching and Learning Excellence, Prince of Songkla University, Thailand. He received B.Ed. in art education and M.Ed. in educational technology and communications from Prince of Songkla University, Thailand, and the Ph.D. in educational communications and technology from Chulalongkorn University, Thailand.

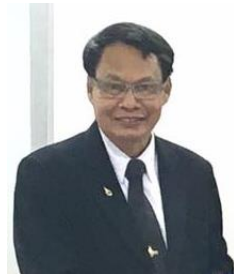

Wasant Atisabda is an assistant professor and the chair of doctoral program in educational leadership and innovation at the Department of Educational Technology, Faculty of Education and also the Director of Research Center for Educational Innovations and Teaching and Learning Excellence, Prince of Songkla University, Thailand. He received B.Ed. in teaching german as second language, and M.Ed. in audio-visual education from Chulalongkorn University, Thailand, the Ed.Sp. in educational technology, and the Ph.D. in higher and continuing education from University of Missouri-Columbia, USA.

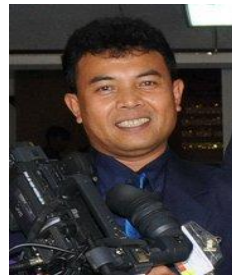

Kittisak Na Patthalung received the B.Ed. in educational technology and the M.Ed. in educational technology and communications from Prince of Songkla University, Thailand. He is the chair of B.Ed. program in educational technology and communications, and also the head of the Department of Educational Technology, Faculty of Education, Prince of Songkla University, Thailand. 